Pesq. Vet. Bras. 30(4):289-294, abril 2010

\title{
Morfologia dos órgãos genitais masculinos do Jurará Kinosternon scorpioides (Chelonia: Kinosternidae) ${ }^{1}$
}

\author{
Rafael Cardoso Carvalho², Sâmia Clara Rodrigues de Oliveira ${ }^{3}$, Pedro Primo \\ Bombonato $^{4}$, Antonia Santos Oliveira ${ }^{5}$ e Alana Lislea de Sousa ${ }^{5 *}$
}

\begin{abstract}
Carvalho R.C., Oliveira S.C.R., Bombonato P.P., Oliveira A.S. \& Sousa A.L. 2010. [Morphology of the male genital organs of the Scorpion Mud Turtle Kinosternon scorpioides (Chelonia: Kinosternidae).] Morfologia dos órgãos genitais masculinos do Jurará Kinosternon scorpioides (Chelonia: Kinosternidae). Pesquisa Veterinária Brasileira 30(4):289-294. Departamento das Clínicas do Curso de Medicina Veterinária, Universidade Estadual do Maranhão, Cidade Universitária Paulo VI, Tirirical, São Luís, MA 65050-150, Brazil. E-mail: alana@elo.com.br

Kinosternon scorpioides is a small semi-aquatic turtle, typical of fresh-water, with wide geographic distribution. It is found in the state of Maranhão, where is called jurará or muçuã. Its meat is an excellent protein source and despite current legislation, it is commercialized at beaches and markets in the city of São Luis, consumed in restaurants as an appetizer in its own shell. The constitutive elements of the male genital organs were studied, aiming to provide morphological data of the species which could be used in reproductive biology aimed at actions towards its preservation in captivity. The sample was composed of 10 adult males, captured by IBAMA-MA (Proc. oㅜ 020.12.002400/99-31, license ํㅡ 002/01), euthanized, following rules from the Ethics Committee of UEMA's Veterinary Medicine School. The choelomic cavity was opened and the organs were fixed in formaldehyde $10 \%$ and subsequently dissected. The testis of $K$. scorpioides had ovoid shape and golden yellow coloration. The cylindrical epididymidis adhered dorsal-wise to the medial surface of the testis, ending in a small deferent duct. The deferent ducts did not form distinct blister and opened inside cloaca. The furrowed penis, located in the base of the cloaca, extending itself until the tail and it was composed by root, body and free part. The morphology data of the reproductive organs of these animals was similar to other turtles such as the sea turtle, suggesting a conservative morphological presentation among turtles.
\end{abstract}

INDEX TERMS: Anatomy, male genital organs, jurará, muçuã, Kinosternon scorpioides.

${ }^{1}$ Recebido em 17 de março de 2009.

Aceito para publicação em 10 de agosto de 2009.

2 Centro de Ciências Agrárias e Ambientais (CCAA), Universidade Federal do Maranhão (UFMA), Campus IV, BR 222 Km 4, Boa Vista, Chapadinha, MA 65500-000, Brasil. E-mail: rafaelcarvalho@ufma.br

3 Pós-Graduanda do Mestrado em Ciências Veterinárias, Universidade Estadual do Maranhão (UEMA), Cidade Universitária Paulo VI s/n, Tirirical, São Luís, MA 65050-150, Brasil.

${ }^{4}$ Programa de Pós-Graduação em Anatomia dos Animais Domésticos e Silvestres, Departamento de Cirurgia, Faculdade de Medicina Veterinária e Zootecnia (FMVZ), Universidade de São Paulo (USP), Av. Prof. Dr. Orlando Marques de Paiva 87, São Paulo, SP 05508-270, Brasil.

${ }^{5}$ Departamento das Clínicas Veterinárias, Centro de Ciências Agrárias (CCA), UEMA, São Luís, MA. *Autor para correspondência: alana@elo.com.br
RESUMO.- Kinosternon scorpioides é uma pequena tartaruga semi-aquática, típica de água doce, de distribuição geográfica bastante diversificada, encontrada no estado do Maranhão, onde é denominada de jurará ou muçuã. Sua carne é uma excelente fonte de proteína e a despeito da legislação vigente, é comercializado nas praias e feiras da cidade de São Luís e consumido nos restaurantes sob a forma de farofa servida em casquinha. Os órgãos genitais do macho foram estudados visando fornecer dados morfológicos da própria espécie, que poderão ser utilizados na biologia reprodutiva voltada para ações de preservação em cativeiro. Compõe-se a amostra de 10 machos adultos, obtidos mediante apreensões do IBAMA-MA (Proc. $n^{\circ} 020.12 .002400 / 99-31$, licença $n^{\circ}$ $002 / 01$ ), os quais foram eutanaziados conforme normas 
do Comitê de Ética do Curso de Medicina Veterinária, Universidade Estadual do Maranhão. A cavidade celomática foi aberta e os órgãos fixados em solução aquosa de formaldeído $10 \%$, e posteriormente dissecados. Os testículos possuem formato ovóide e coloração amarelo-ouro. Os epidídimos convolutos estavam aderidos dorsalmente à superfície medial dos testículos, terminando em um pequeno ducto deferente. Os ductos deferentes não formaram nenhuma ampola distinta, abrindo-se na cloaca. $\mathrm{O}$ pênis sulcado, localizado no assoalho da cloaca, estendeu-se até a cauda, composto de raíz, corpo e glande. A morfologia dos órgãos reprodutivos destes animais assemelha-se aos de outras tartarugas, sugerindo uma morfologia conservada entre as tartarugas.

TERMOS DE INDEXAÇÃO: Anatomia, órgãos genitais masculinos, jurará, muçuã, Kinosternon scorpiodes.

\section{INTRODUÇÃO}

Kinosternon scorpioides é um pequeno réptil da ordem dos quelônios pertencente à família Kinosternidae. Tratase de uma pequena tartaruga de água doce, com tamanho médio de 16 a $18 \mathrm{~cm}$, típico das várzeas da região amazônica, onde é conhecida como muçuã, sendo no Maranhão chamada de jurará. Geograficamente distribuise desde as regiões da Amazônia e caatinga brasileira, Peru, Colômbia, Venezuela, Guianas, até o norte da Argentina (Bramble et al. 1984, Rocha \& Molina 1987, AcuñaMensen 1994, Carvalho et al. 2000, Delbuque 2000). Como características gerais, o jurará apresenta os quatro membros curtos como pilares, com cinco dedos ligados por membranas interdigitais, um casco ósseo convexo e alto, recoberto por escamas córneas, a carapaça, e outro ventral o plastrão. Freqüentam a água, vivendo preferencialmente em locais alagadiços, embora em algumas épocas do ano (períodos secos) vivam em regiões secas. São animais onívoros alimentando-se de algas, restos de vegetais, insetos, girinos e rãs (Carvalho et al. 2000, Machado Júnior et al. 2006).

Dentre as tartarugas brasileiras, o muçuã é uma das menos conhecidas pela ciência e provavelmente uma das mais ameaçadas. Apesar da caça ser proibida, no Maranhão e no Pará, ela é tida como iguaria da culinária local, e é servida clandestinamente em hotéis e restaurantes finos, onde sua carne é preparada com farofa e servida sobre o casco a semelhança da casquinha de siri, enquanto nas praias são vendidos em dúzias, vivos e pendurados, do mesmo modo como se faz com o caranguejo (Delbuque 2000, Machado Júnior et al. 2006).

O futuro desta espécie está ameaçado pelas queimadas, poluição, desmatamento e caça indiscriminada, já que a sua captura é feita em larga escala, não havendo estimativas precisas sobre os estoques existentes na natureza, mas sabe-se que a população está diminuindo bruscamente (Rocha \& Molina 1987).

Com relação a biologia reprodutiva desta espécie, possuem dimorfismo sexual externo bastante evidente. Os machos adultos são maiores que as fêmeas, com plastrão côncavo, o que facilita a monta para a cópula, e a cauda maior e mais grossa com apêndice córneo em sua extremidade, enquanto nas fêmeas o plastrão encontra-se plano e a cauda mais curta. A fecundação é interna com a reprodução através de ovos (Orr 1986, Hildebrand 1995, Storer et al. 2000). No ritual de cópula do muçuã o macho morde a borda da carapaça da fêmea, o que possivelmente trata-se de um ritual de corte. O macho inicia este ato promovendo um ruído, sacudindo a cabeça e cheirando os pés e a cloaca da fêmea, prosseguindo então a monta na parte traseira, galopeando a região anal do seu plastrão em encontro a carapaça da fêmea que grune durante a cópula, e o macho segura a fêmea com os quatro membros e a cauda ficando com o pescoço inteiramente esticado, havendo indícios que o acasalamento pode ocorrer em qualquer época do ano (Castaño-Mora 1985, Delbuque 2000).

Embora alguns aspectos biológicos sejam relatados, não há informações referentes à morfologia dos órgãos genitais desta espécie, o que motivou a busca de embasamento teórico na classe dos répteis, e em especial, a ordem dos quelônios, representados pelas tartarugas e também em outros vertebrados. Para tanto, Noble \& Noble (1940) e Ashley (1969) informam que os órgãos genitais masculinos de quelônios constituem-se de um par de testículos, epidídimos, ductos deferentes e um pênis. Os testículos são pares, arredondados de cor amarela, fixados na face ventral de cada um dos rins, onde cada um se liga com a superfície anterior do epidídimo. O pênis é erétil e localiza-se na parede ventral da cloaca. O epidídimo se conecta aos ductos deferentes, e estes adentram a cloaca próxima à base de abertura da vesícula urinária.

Reconhecendo a ameaça de extinção, importância econômica, insuficiência de dados bibliográficos sobre esta espécie, principalmente no que discerne aos aspectos morfológicos, objetivou-se com esta pesquisa descrever a anatomia dos órgãos genitais masculinos de $K$. scorpioides, caracterizando anatomicamente seus componentes, delineando a sua topografia, examinando e analisando possíveis variações morfológicas existentes e comparando-as com as espécies mais próximas, no intuito de assentar bases morfológicas as quais contribuirão com o estudo da anatomia comparada de quelônios e répteis, e também servirão de subsídios para pesquisas aplicadas, como a fisiologia e reprodução, auxiliando outras investigações nas áreas da biologia, ecologia e manejo do jurará, favorecendo sua preservação.

\section{MATERIAL E MÉTODOS}

Foram estudados 10 machos adultos, adquiridos mediante apreensões do Instituto Brasileiro do Meio Ambiente e dos Recursos Renováveis (IBAMA), de acordo com a licença $n^{\circ}$ 002/01 e processo n 020.12.002400/99-31. Estes animais foram apreendidos em feiras livres, cabendo ressaltar que muitas vezes estes estavam mutilados, o que inviabilizava a sua reintrodução na natureza. Dados biométricos foram obti- 
dos e antes de serem submetidos à eutanásia com aplicação de tiopental sódico $2,5 \%$ no volume letal de $3 \mathrm{~mL}$ por via intraperitoneal, conforme recomendação do Comitê de Ética do Curso de Medicina Veterinária da UEMA. Após a eutanásia, caracterizado por relaxamento muscular, a abertura da cavidade celomática foi realizada com auxílio de uma serra de aço, para desarticulação da ponte óssea que une a carapaça ao plastrão, com remoção deste último. Após observações a fresco da topografia dos órgãos genitais masculinos, as peças foram fixadas em solução aquosa de formaldeído $10 \%$ por no mínimo 24 horas, e posteriormente dissecadas, e fotografadas para confirmação dos achados.

\section{RESULTADOS E DISCUSSÃO}

Os 10 machos adultos de Kinosternon scorpioides apresentaram peso médio de $320,2 \mathrm{~g}$, morfologia de carapaça com $13 \mathrm{~cm}$ por $8,2 \mathrm{~cm}$ e plastrão $\mathrm{com} 11,8 \mathrm{~cm}$ por $5,3 \mathrm{~cm}$, correspondentes respectivamente ao comprimento e largura. Os órgãos genitais do jurará macho estão constituídos por testículos, epidídimos, ductos deferentes e pênis (Fig.1A).

Em répteis e vertebrados de forma geral, Noble \& Noble (1940) e Ashley (1969) afirmam que o aparelho genital dos quelônios machos é constituído por um par de testículos, epidídimos, ductos deferentes e um pênis.

Na ordem dos répteis, Baroudi (1970), relata estes órgãos formados por dois testículos globosos, dos quais partem os respectivos canais deferentes para se unirem aos ureteres correspondentes, que funcionam como condutores de urina e espermatozóides na sua porção justacloacal.

Nos vertebrados em geral, Barros (1971) e Hildebrand (1995), afirmam que o aparelho reprodutor masculino é formado por uma porção secretora que é representada pelo testículo, formado por canais seminíferos, que elaboram os espermatozóides para a reprodução e uma glândula intersticial, que produz hormônios para o desenvolvimento dos caracteres sexuais secundários; e uma porção excretora, representada pelo epidídimo, canal deferente e pênis. Enquanto nos mamíferos existem também glândulas acessórias a este sistema. Neste aspecto pôdese observar a semelhança de constituintes dos órgãos genitais masculinos em $K$. scorpiodes, uma vez que se relata a presença de um par de testículos, epidídimos, ductos deferentes e pênis, a exceção das glândulas acessórias, as quais não foram evidenciadas macroscopicamente neste estudo. No jurará os testículos são em número de dois, situados no interior da cavidade celomática, craniolateralmente à cintura pélvica, dispostos assimetricamente em cada lado da linha média, com o direito se apresentado mais cranial ao esquerdo. Fox (1977) descreve localização e assimetria na posição dos testículos semelhantes para alguns lagartos e cobras. Hildebrand (1995) afirma que é comum a assimetria de posição desse órgão em vertebrados. Este mesmo autor afirma que os testículos podem estar parcialmente fundidos entre si nos elasmobrânquios. Romer \& Parsons (1985) descrevem nos ciclóstomos uma estrutura única e não um par. Em mamíferos (Romer \& Parsons 1985, Dyce et al. 1997) comentam que o testículo esquerdo tende a ser ligeiramente maior que o direito, entretanto, não foi observado a assimetria de tamanho para os testículos no mesmo animal aqui estudados.

Quanto ao aspecto funcional, autores como Barros (1971) e Dyce et al. (1997) afirmam que estes órgãos representam à porção secretora do aparelho genital masculino dos vertebrados, sendo estes responsáveis pela elaboração dos espermatozóides e hormônios para o desenvolvimento dos caracteres sexuais secundários onde os mesmos combinam elementos endócrinos e exócrinos no interior de uma cápsula comum. A partir da morfologia apresentada por estes órgãos no Jurará, pôde-se deduzir que as funções testiculares são as mesmas relatadas por Barros (1971) e Dyce et al. (1997), para vertebrados e mamíferos em geral.

No que concerne à anatomia macroscópica dos testículos, no jurará estes se apresentam de formato ovóide, de tamanho e coloração variáveis. A variação no tamanho entre os exemplares estudados é justificada pela diferença de tamanho entre os animais. A coloração variou do amarelo-claro ao amarelo-ouro, provavelmente em virtude da atividade reprodutiva (Fig.1B). Noble \& Noble (1940) e Ashley (1969), descrevem forma e coloração semelhante para aves e tartarugas, entretanto não enfatizam mudança de coloração em virtude de atividade ou período reprodutivo. Porém Fox (1977) cita que os testículos de Vipera berus são cilíndricos e alongados, amarelo-esbranquiçados. Para este mesmo autor, os testículos de répteis são similares aos de aves e mamíferos. A superfície dos testículos do jurará encontra-se recoberta pela delgada túnica albugínea, ausentes de septos e lobulações (Fig.1A,B), achados semelhantes aos de King (1975) para aves.

Os testículos no jurará encontram-se fixados por pregas peritoneais: o mesórquio e o mesocólon. O primeiro fixa o testículo ao epidídimo, ducto deferente, ao rim e glândula adrenal, em cada lado correspondente; enquanto o segundo ao cólon e aos pulmões (Fig.1C). Ashley (1969) e Fox (1977) referenciam situação análoga para tartarugas.

No jurará os epidídimos estão presentes em número de dois, situados ao longo da parte dorsal da superfície medial de cada testículo, apresentando-se como um elemento estrutural delicado, dando continuidade aos ductos deferentes (Fig.1A,C). Os epidídimos e canais deferentes, de acordo com Barros (1971), representam a parte secretora do aparelho reprodutor masculino. São eles os responsáveis pelo transporte dos espermatozóides produzidos nos testículos. Ashley (1969) relata localização semelhante para tartarugas e King (1975) e Dyce et al. (1987) para aves. Romer \& Parsons (1985), afirmam que os ciclóstomos não possuem um sistema de ductos de transporte dos produtos sexuais, entretanto, estes elementos foram evidenciados no jurará. Anatomicamente apresentam-se como estruturas bastantes convolutas de 

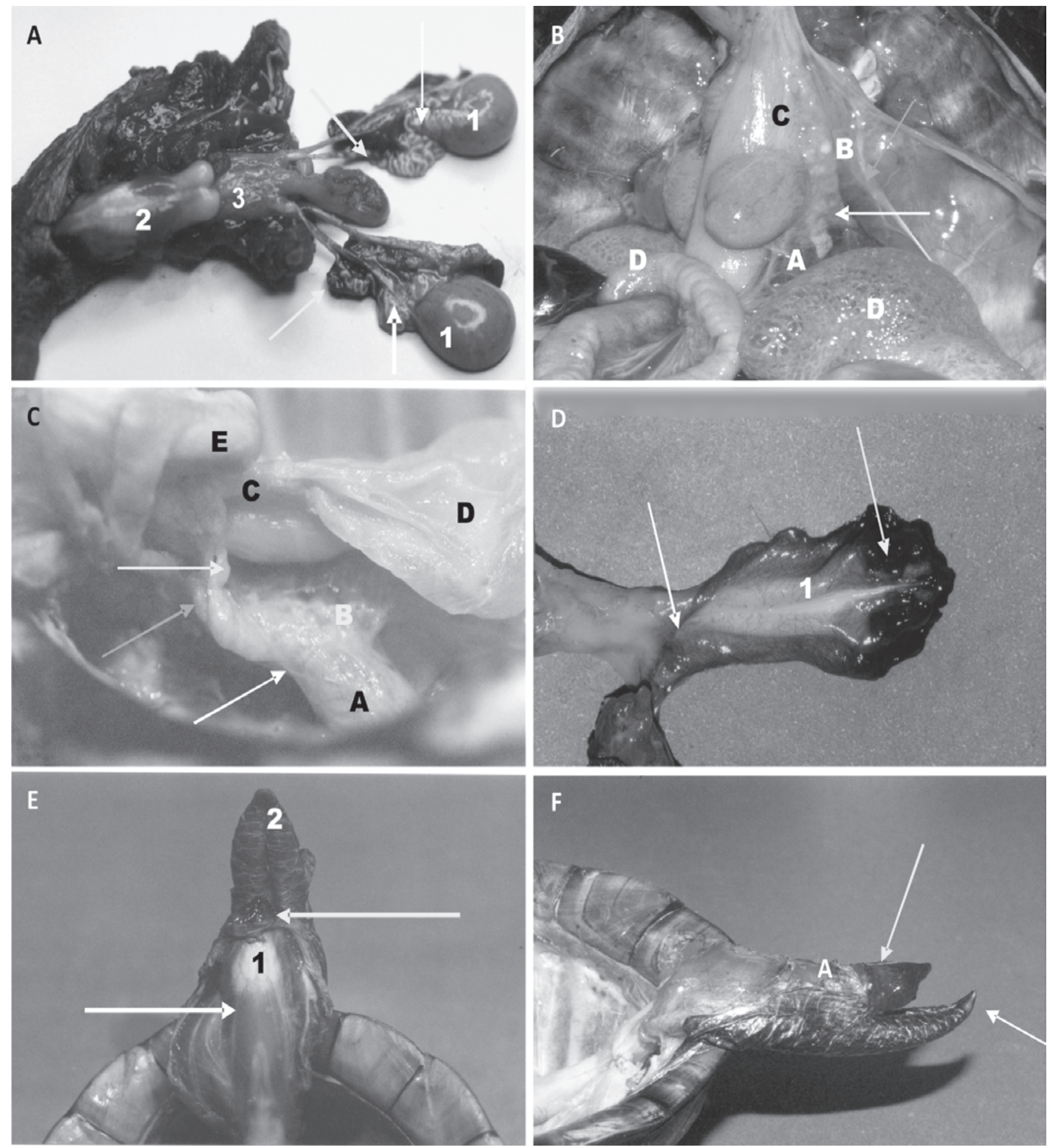

Fig.1. Órgãos reprodutores de Kinosternon scorpioides. (A) Órgãos reprodutores removidos da cavidade celomática em vista ventral: (1) Testículos; seta branca = Epidídimos; seta amarela = Ductos deferentes; (2) Pênis; (3) Cloaca. (B) Na cavidade em vista ventral, testículo fixado pelo mesórquio (A) ao epidídimo (B), rins (seta azul) e glândula adrenal (seta branca). (C) Cólon; (D) Pulmões. (C) Na cavidade em vista ventral, epidídimo fixado ao testículo (A), rim e glândula adrenal (B) pelo mesórquio (seta branca). (C) Uretra; (D) Vesícula urinária; (E) Raiz do pênis; seta amarela = Ducto deferente; seta azul = ureter. (D) Removido da cavidade em vista dorsal, pênis como um órgão sulcado, composto de raiz (seta branca), (1) corpo e glande =em seta amarela, de cor enegrecida e em formato de couve-flor. (E) Em vista ventral, pênis (1) fixado pelo músculo retrator do pênis (seta branca) e protegido pelo prepúcio (seta amarela), em (2) cauda. (F) Em vista lateral, (A) pênis retraído no prepúcio, e a glande (seta amarela) repousando no assoalho da cloaca. Unha córnea da cauda em seta branca. 
coloração esbranquiçada e inseridos aos testículos pelo mesórquio. Os espermatozóides são produzidos no interior dos testículos e são conduzidos pelos ductulos eferentes aos epidídimos. Estes achados também foram citados por Noble \& Noble (1940), Ashley (1969) para tartarugas e Fox (1977) para cobras. Entretanto, para $K$. scorpiopides, não foi evidenciada a diferenciação anatômica em cabeça, corpo e cauda do epidídimo, como ocorre em mamíferos (Ellenport 1975, Dyce et al. 1997).

Os ductos deferentes no jurará são estruturas simples, em número de dois, de trajeto convoluto que se estendem do epidídimo até a cloaca, seguindo lateralmente aos ureteres, tendo como função o transporte dos espermatozóides (Fig.1C). Para Hildebrand (1995) em répteis, os ductos deferentes além de conduzirem os espermatozóides, o armazenam temporariamente, e se contraem durante a cópula para ejacular seu conteúdo, fato este não comprovado nesta pesquisa. Tem seu trajeto paralelo à linha média e a parte renal do ureter, e desembocam lateralmente a este, na superfície dorsal da cloaca. Diferentemente como ocorre no jurará, Baroudi (1970) afirma que nos lagartos os ductos deferentes se unem aos ureteres correspondentes, os quais funcionam como condutores de urina e espermatozóide na sua porção justacloacal, onde esta fusão ocorre na porção terminal do ureter. Ashley (1969) e Fox (1977) em descrição para tartarugas relatam que os ductos deferentes são convolutos na sua região anterior, próximo ao epidídimo e um tubo sinuoso na sua região posterior. Formatos estes similares aos encontrados no Jurará, entretanto diferentemente do que é citado aos mamíferos por (Hildebrand 1995, Dyce et al 1997) em K. scorpioides não foram evidenciados nos epidídimos a formação de ampolas e ou dilatações.

O pênis, órgão copulador é bastante discutido na ordem dos répteis e em outras ordens de vertebrados. Segundo Romer \& Parsons (1985), os ciclostomados e peixes ósseos não possuem órgãos copuladores, entretanto estruturas especializadas são desenvolvidas para facilitar a entrada dos espermatozóides nos tubos genitais femininos; Por outro lado, Hildebrand (1995) afirma que os anfíbios voltam à água para procriar, com fecundação externa, demonstrando ser desnecessário a presença de órgãos copuladores. Mas, Kukenthal \& Matthes (1969) afirmam que os órgãos copuladores nos sáurios e ofídios são em forma de cecos pares, que podem ser desvaginados, enquanto nos crocodilianos e quelônios contrariamente, apresentam formações maciças e ímpares necessária à cópula. Para os répteis, Fernandes (1981), Orr (1986), Villee et al. (1988), Hildebrand (1995) e Storer et al. (2000) relatam que os machos desenvolveram órgãos copuladores especiais que introduzem os espermatozóides diretamente no sistema reprodutor da fêmea. A fecundação é interna e os delicados espermatozóides não são expostos ao meio. Além disso, eles afirmam que os répteis desenvolveram dois tipos de órgãos copuladores: nos lagartos e serpentes, há estru- tura par na cloaca, chamada hemi-pênis, que serve para este propósito; enquanto crocodilos e tartarugas possuem uma estrutura que pode ser homóloga ao pênis dos mamíferos. No jurará, o pênis é um órgão muscular ímpar, localizado no assoalho da cloaca, envolvido por uma delgada membrana que corresponde a bainha prepucial de mamíferos, portanto, não sendo visível em estado de repouso (Fig.1E,F). A localização do pênis do jurará assemelha-se aos relatos feitos por Ashley (1969) para tartarugas Chrysemys sp., Carvalho et al. (2003) para o Geochelone carbonaria (jabuti das "patas vermelhas"), King (1975) e Dyce et al. (1997), para aves. Todavia, Baroudi (1970) relata que as tartarugas apresentam no interior da cloaca dois órgãos penianos, que apresentam corpos cavernosos que se enchem de sangue, permitindo assim ereção e cópula. No Jurará trata-se de um órgão sulcado ventralmente, composto de raiz, corpo e glande (Fig.1D,F). A raiz compreende a porção bulbar, que é a parte inicial do órgão, consistência firme de coloração esbranquiçada; o corpo é composto por dois corpos cavernosos, separados por um sulco, por onde escorre o sêmen e a glande enegrecida, em forma de couve-flor, é a porção terminal do órgão (Fig.1D). Assim também descreveram estes aspectos, Noble \& Noble (1940) e Ashley (1969) para as tartarugas e Carvalho et al. (2003) para G. carbonaria. Entretanto, King (1975) e Dyce (1987) relatam ao galo uma estrutura denominada falo, que é diferente da apresentada por $K$. scorpioide. A morfologia do pênis desta espécie sugere que durante a estimulação sexual, os esfincteres diminuem o escoamento sanguíneo, causando assim seu intumescimento, o que resulta na protusão, havendo o fechamento do sulco formado pelos corpos cavernosos, no qual, no momento da ejaculação, a secreção escorre, sendo então este órgão destituído de uretra. Estes achados são referendados de forma pouco clara e específica nos trabalhos de Romer \& Parsons (1985) e Hildebrand (1995) para tartarugas os quais relatam que durante a estimulação sexual, esfíncteres diminuem o escoamento sanguíneo, causando assim o intumescimento desse órgão, que fecha o sulco, e o pênis se protai da cloaca funcionando como órgão intermitente.

\section{CONCLUSÕES}

Com base nos resultados obtidos, segundo a metodologia proposta, conclui-se que os órgãos genitais masculinos do muçuã (Kinosternon scorpioides) são constituídos por um par de testículos de formato ovóide, coloração variável em tons amarelos, posicionados assimetricamente no interior da cavidade celomática e fixados pelo mesórquio e o mesocólon, seguidos de epidídimos convolutos ligados a superfície medial de cada testículo, e contínuos aos ductos deferentes, que se abrem no interior da cloaca, com o pênis, órgão de copulação dividido em raiz, corpo e glande, demonstrando que os órgãos genitais dessa espécie são semelhantes aos quelônios, não sendo evidenciado a presença de glândulas anexas, 
assim como variação anatômica nos exemplares estudados.

Agradecimentos.- À Universidade Estadual do Maranhão (UEMA), ao Instituto Brasileiro do Meio Ambiente e dos Recursos Naturais Renováveis (IBAMA) e ao CNPq/Bolsista PIBIC.

\section{REFERÊNCIAS}

Acuña-Mensen R.A. 1994. Morphomeric variation and ecological characteristics of the habitat of the Scorpion Mud Turtle Kinosternon scorpioides in Costa Rica (Chelonia, Kinosternidae). Revta Bras. Biologia 4(3):537-547.

Ashley L.M. 1969. Laboratory Anatomy of Turtle. $6^{\text {th }}$ ed. W.C. Brown Company Publishers, Debuque. 47p.

Baroudi R. 1970. Elementos da Zoologia. 6aㅡ ed. Nobel, São Paulo, p.125152.

Barros A. 1971. Zoologia. 16 ed. Nobel, São Paulo, p.361-370.

Bramble D.M., Hutchison J.H. \& Leagler J.M. 1984. Kinosternid shell kineses: Structure, function and evolution. Copeia, Lawrence, 2:456475.

Carvalho R.C., Sousa A.L., Moura C.E.B., Faria T.N., Costa W.P., Resende H.R.A., Pereira H.M. \& Mariana A.N.B. 2003. Morfologia do pênis do jabuti das patas vermelhas (Geochelone carbonaria, SPIX: 1824). Revta Bras. Reprod. Anim. 27(2):229-230.

Carvalho R.C., Sousa A.L., Silva A.L.A., Pereira J.G., Santos D.M.S., Pereira P.D.J. \& Anceles F.K.L. 2000. Anatomia da traquéia e pulmão do muçuã (Kinosternon scorpioides). Braz. J. Morphol. Sci. 17(1):165-166.

Castaño-Mora O.V. 1985. Notas adicionales sobre la reproducción y el crescimento de los mocorrocoyes (Geochelone carbonaria y $G$. denticulata, Testudines, Testudinidae). Lozania 52:1-5.
Delbuque M. 2000. Ficha do bicho: muçuã. Globo Rural 176:83-84.

Dyce K.M., Sack W.O. \& Wensing C.I.G. 1997. Tratado de Anatomia Veterinária. Guanabara Koogan, Rio de Janeiro. 798p.

Ellenport C.R. 1975. Aparelho urogenital geral, p.136-137. In: Getty R. (Ed.), Anatomia dos Animais Domésticos. 5를 ed. Guanabara Koogan, Rio de Janeiro.

Fernandes V. 1981. Zoologia. $7^{\text {ạ }}$ ed. Pedagógica e Universitária, São Paulo, s.p.

Fox H. 1977. The urogenital system of the reptiles, p.1-127. In: Gans C. (Ed.), Biology of Reptilia. Academic Press, New York.

Hildebrand M. 1995. Análise das Estruturas dos Vertebrados. Atheneu, São Paulo, p.299-311.

King A.S. 1975. Aparelho urogenital das aves, p.1798-1805. In: Getty R. (Ed.), Anatomia dos Animais Domésticos. 5aㅡ ed. Guanabara Koogan, Rio de Janeiro.

Kükental W. \& Matthes E. 1969. Guia de trabalhos práticos de zoologia. 15a ed. Atlântida Editora, Rio de Janeiro, p.391-409.

Machado Júnior A.A.N., Sousa A.L., Santos F.C.F. \& Pereira J.G. 2006. Morfologia dos órgãos genitais femininos do muçuã (Kinosternon scorpioides). Arch. Vet. Sci. 11(2):25-29.

Noble G.A. \& Noble E.R. 1940. A Brief Anatomy of Turtle. Hamphrey Oxford University Press, London. 49p.

Orr R.T. 1986. Biologia dos Vertebrados. $5^{\mathrm{a}}$ ed. Roca, São Paulo. 505p.

Rocha M.B. \& Molina F.B. 1987. Algumas observações sobre a biologia e manejo do muçuã. Aquacultura 2:25-26.

Romer A.S. \& Parsons T.S. 1985. Anatomia Comparada dos Vertebrados. Atheneu, São Paulo, p.321-358.

Storer T.I., Usinger R.L., Stebbins R.C. \& Nybakken J.W. 2000. Zoologia Geral. 6ª ed. Companhia Editora Nacional, São Paulo, p.642-654.

Villee C.A., Walker Júnior W.F. \& Barnes R.D. 1988. Zoologia Geral. 6a ed. Guanabara Koogan, Rio de Janeiro, p.547-557. 